\title{
Post-combustion carbon dioxide capture using electrochemically mediated amine regeneration
}

Cite this: Energy Environ. Sci., 2013, 6, 2505

Received 5th April 2013

Accepted 5th June 2013

DOI: $10.1039 / c 3 e e 41165 f$

www.rsc.org/ees

\author{
Michael C. Stern, ${ }^{a}$ Fritz Simeon, ${ }^{a}$ Howard Herzog ${ }^{b}$ and T. Alan Hatton ${ }^{\star a}$
}

Electrochemically mediated amine regeneration is a new post-combustion capture technology with the potential to exploit the excellent removal efficiencies of thermal amine scrubbers while reducing parasitic energy losses and capital costs. The improvements result from the use of an electrochemical stripping cycle, in lieu of the traditional thermal swing, to facilitate $\mathrm{CO}_{2}$ desorption and amine regeneration; metal cations generated at an anode react with the amines, displacing the $\mathrm{CO}_{2}$, which is then flashed off, and the amines are regenerated by subsequent reduction of the metal cations in a cathode cell. The advantages of such a process include higher $\mathrm{CO}_{2}$ desorption pressures, smaller absorbers, and lower energy demands. Several example chemistries using different polyamines and copper are presented. Experimental results indicate an open-circuit efficiency of $54 \%$ (15 kJ per mole $\left.\mathrm{CO}_{2}\right)$ is achievable at the tested conditions and models predict that $69 \%$ efficiency is possible at higher temperatures and pressures. A bench scale system produced $1.6 \mathrm{~mL} \mathrm{~min}{ }^{-1} \mathrm{CO}_{2}$ while operating at 0.4 volts and $42 \%$ Faradaic efficiency; this corresponds to a work of less than $100 \mathrm{~kJ}$ per mole.

\begin{abstract}
Broader context
For the next several decades, coal will remain one of the most utilized sources of electricity in the world. While coal is cheap and abundant, it is also the dirtiest form of fossil fuel. Just one coal-fired power plant emits 100's of metric tons per hour of carbon dioxide $\left(\mathrm{CO}_{2}\right)$; enough to fill the Empire State Building five times per day. Carbon capture and sequestration is the only way to satisfy the world's growing energy demands while addressing climate change. Many technologies exist to capture the $\mathrm{CO}_{2}$ from the flue gas leaving a powerplant. Thermal amine scrubbing is the most developed of these technologies, but is inefficient, capitally expensive, and inapplicable to existing power plants. Electrochemically Mediated Amine Regeneration (EMAR) is new a technology, developed at MIT, which addresses many of the shortcomings of thermal scrubbing while remaining similar enough that the process could be rapidly deployed by industry. We show through modeling and experiments that the EMAR system should be capable at of separating $\mathrm{CO}_{2}$ for less than $15 \mathrm{~kJ}$ per mole with low current densities at $70{ }^{\circ} \mathrm{C}$. Our bench-scale system, running at room temperature, operates at $100 \mathrm{~kJ}$ per mole.
\end{abstract}

\section{Introduction}

Environmental projections indicate that significant economic and humanitarian consequences will result from continuing climate change unless preventative actions are taken. Since 1880 , the average world temperature has increased by $0.06^{\circ} \mathrm{C}$ per decade. Since 1970 , that rate has nearly tripled to $0.16^{\circ} \mathrm{C}$ per decade, which is unparalleled in the last 11000 years. ${ }^{1,2}$ This increase in temperature is highly correlated with the carbon dioxide $\left(\mathrm{CO}_{2}\right)$ concentration in the atmosphere. ${ }^{3}$ Famines, floods, and more destructive storms are expected as a result of the increasing global temperature. ${ }^{4,5}$ To minimize the impact of these natural disasters, the National Research Council has recommended a substantial reduction in $\mathrm{CO}_{2}$ emissions in the

${ }^{a}$ Department of Chemical Engineering, Massachusetts Institute of Technology, 77 Massachusetts Ave., 66-325, Cambridge, MA, 02139, USA. E-mail: tahatton@mit. edu; Tel: +1617 253-4588

${ }^{b}$ MIT Energy Initiative, Massachusetts Institute of Technology, Cambridge, MA 02139, USA coming decades. ${ }^{6}$ The EPA estimates that in $2010,40 \%$ of the $\mathrm{CO}_{2}$ emissions in the United States originated from power generation. ${ }^{7}$ Coal will remain an important component of electricity production even with the recent reduction in natural gas prices and is still projected to account for $38 \%$ of electricity generation in 2035, while the share produced from natural gas will increase to $28 \% .^{8,9}$ Post-combustion capture of $\mathrm{CO}_{2}$ from coal-fired and gas-fired power plants has, therefore, been identified as a necessary strategy for reducing anthropogenic emissions. ${ }^{10}$ Capture of anthropogenic $\mathrm{CO}_{2}$ is also predicted to become useful for enhanced oil recovery operations as natural sources of $\mathrm{CO}_{2}$ become depleted over the next few decades.. ${ }^{11}$

Today's state of the art technology for carbon capture, thermal amine scrubbing, ${ }^{12}$ exhibits excellent removal efficiencies and produces high purity $\mathrm{CO}_{2}$ outlet streams for storage or utilization, but the significant steam and capital expenses are an impediment to its implementation on a large scale. Although research and development of new amines, blends of amines, and amine mixtures with carbonates are being pursued by many industrial and academic groups to improve the prospects for 
installation of thermal amine scrubbing units, ${ }^{\mathbf{1 3 - 1 6}}$ they have not yet led to major reductions in capital and operating costs. ${ }^{17-19}$

Electrically driven processes such as pressure or vacuum swing adsorption or membrane separation are gaining significant attention because they avoid many of the logistical challenges and inefficiencies associated with thermal systems. ${ }^{20-22}$ Retrofits, for example, are extremely challenging with a thermal system because of plant-wide modifications required to divert the tremendous quantity of steam needed for the stripper. These electrical systems do have the drawback, however, that they produce outlet streams with lower $\mathrm{CO}_{2}$ purity than do the thermal systems, and may need to be augmented by refrigeration processes to achieve outlet streams suitable for compression and transportation. ${ }^{17,23}$

In this paper, we introduce a new concept for carbon capture, Electrochemically Mediated Amine Regeneration (EMAR), that combines the advantages of amine scrubbing with the ease of implementation of an electrical process for the stripping cycle. In addition to being capable of producing high purity outlet streams, the EMAR process can be designed to output at pressure with no sweep stream. Desorption at 10 bar would halve the compression costs needed for geological sequestration, and the removal of the sweep stream would eliminate the costs associated with steam generation and with the cooling required to condense the water from the outlet.

Leaner loadings in the sorbent stream entering the absorber can be achieved using the EMAR process instead of the traditional thermal processes. The thermal process can only desorb about half of the $\mathrm{CO}_{2}$ bound to the loaded amines because the desorption temperature is limited by the thermal degradation of the amines. In contrast, the EMAR system should be capable of removing 80 to 90 percent of the absorbed $\mathrm{CO}_{2}$, which would lead to a 30 to 40 percent reduction in sorbent circulation rate. The leaner sorbent will improve absorber efficiency, and thus lead to a reduction in the size of the most capitally expensive unit operation in the $\mathrm{CO}_{2}$ capture plant.

The EMAR system, in addition to reducing logistical challenges and capital expenses, can reduce the parasitic energy losses of the $\mathrm{CO}_{2}$ separation process. Electrochemical systems are often more efficient than their thermochemical counterparts in many cases. For instance, aluminum, despite being the most abundant metal in the Earth's crust, was equal in value to silver before the development of the electrochemical Hall-Heroult process. ${ }^{24}$ Electrodialysis is also a significantly more efficient strategy for the desalination of water compared to thermal distillation. ${ }^{25}$ Electrochemical processes are efficient because they act directly on the target molecules, and not the medium.

Electrically enhanced separations were first performed by Ward in 1970 using a supported liquid membrane. ${ }^{26}$ Since then, electrochemical complexation separations have been investigated for a variety of compounds by Noble and coworkers, ${ }^{27-29}$ among others. For $\mathrm{CO}_{2}$ capture, carbonate systems based on high temperature molten salt fuel cells, lower temperature aqueous salt systems, and electrodialysis have been considered. ${ }^{30-32}$ Organic quinone molecules and aqueous organometallic complexes have been examined for electrochemical complexation separations with $\mathrm{CO}_{2} \cdot{ }^{33,34}$ Scovazzo et al. demonstrated a 1000 fold concentration of $\mathrm{CO}_{2}$ from environmental levels to nearly atmospheric pressure using quinones in organic solvents and ionic liquids. ${ }^{35}$

The EMAR system differs from these previous schemes because the $\mathrm{CO}_{2}$ sorbent and the redox responsive agent are different molecules. In the work of Scovazzo, ${ }^{35}$ for instance, the quinones acted as both the sorbent and redox agent. In the EMAR cycle, the sorbent is an electrochemically inert amine and the redox agent is a transition metal that can switch between its inert metallic state and its acidic cation form, which competes aggressively with $\mathrm{CO}_{2}$ for the amines; the displaced $\mathrm{CO}_{2}$ is released and flashed off as a gas. By separating the responsibilities for the sorbent and the redox responsive species, the number of possible chemistries that can be utilized in such separations processes increases dramatically.

This paper explores the amine-copper chemistry and its impact on the effectiveness of $\mathrm{CO}_{2}$ capture and release in an electrochemically mediated cycle. Other combinations of transition metals and basic ligands may exist, but the amine-copper system is particularly attractive because of the proven ability of amines to capture $\mathrm{CO}_{2}$ and the significant knowledge base regarding copper electrochemistry. Four polyamines, which have been previously considered for thermal scrubbing of $\mathrm{CO}_{2}$, have been investigated as $\mathrm{CO}_{2}$ sorbents in the EMAR process: ethylenediamine (EDA), ${ }^{36,37}$ aminoethylethanolamine (AEEA), ${ }^{38}$ diethylenetriamine (DETA), ${ }^{39}$ and triethylenetetramine (TETA). ${ }^{40}$ Polyamines were chosen because they form more stable copper complexes, thereby facilitating a more complete desorption of $\mathrm{CO}_{2}$ and reducing the possibility of copper salt precipitation, than do the more common ethanolamines.

\section{The EMAR cycle}

Fig. 1a shows the cyclic reaction scheme of an EMAR process with EDA and copper. The scheme consists of three chemical or electrochemical transitions, which take place in an absorber, an anode, and a cathode. A schematic diagram of the EMAR scrubbing process is shown in Fig. $1 \mathrm{~b}$ with a more detailed view of the electrochemical cell stack in Fig. 1c. In the scrubbing process, the absorber is analogous to an absorber in a thermal scrubbing system. A pump is placed after the absorber to pressurize the electrochemical cell, which allows for the $\mathrm{CO}_{2}$ to be exhausted at pressure. The $\mathrm{CO}_{2}$ is removed in flash tanks placed after the anode sections. The electrodes in the anode and cathode chambers could be either porous copper foam, porous conductive supports plated with copper, or thin channels with copper-plated walls. The membrane could be either an anion exchange membrane or a surfactant coated microporous polyolefin membrane. The electrochemical cells would be stacked in series, similar to a fuel cell stack, to decrease resistive losses.

The generic EMAR cycle is based on three reactions that occur in the absorber, the anode, and the cathode, respectively:

$$
\begin{aligned}
& \mathrm{Am}(\mathrm{aq})+m \mathrm{CO}_{2}(\mathrm{~g}) \rightleftharpoons \mathrm{Am}\left(\mathrm{CO}_{2}\right)_{m}(\mathrm{aq}) \\
& \frac{2}{m} \mathrm{Am}\left(\mathrm{CO}_{2}\right)_{m}(\mathrm{aq})+\mathrm{Cu}(\mathrm{s}) \rightleftharpoons \mathrm{CuAm}_{2 / m}{ }^{2+}(\mathrm{aq})+2 \mathrm{CO}_{2}(\mathrm{~g})+2 \mathrm{e}^{-} \\
& \mathrm{CuAm}_{2 / m}{ }^{2+}(\mathrm{aq})+2 \mathrm{e}^{-} \rightleftharpoons \mathrm{Cu}(\mathrm{s})+\frac{2}{m} \mathrm{Am}(\mathrm{aq})
\end{aligned}
$$



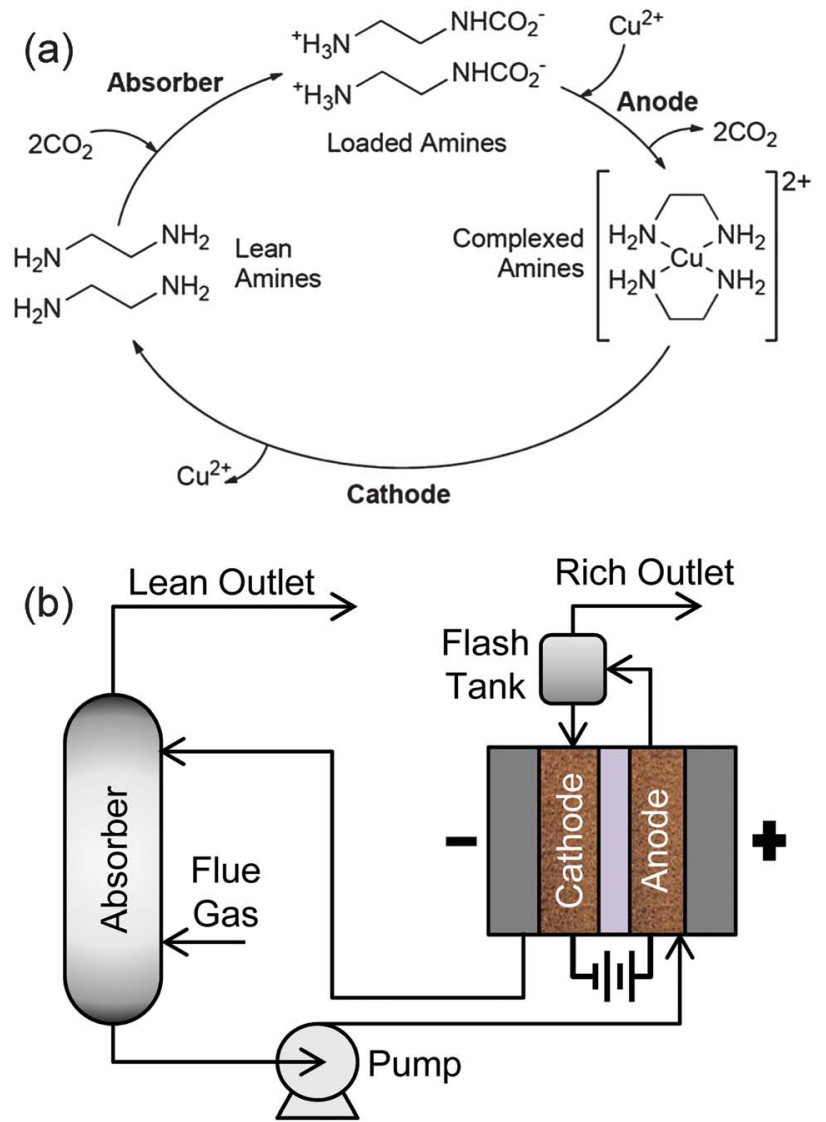

(c)

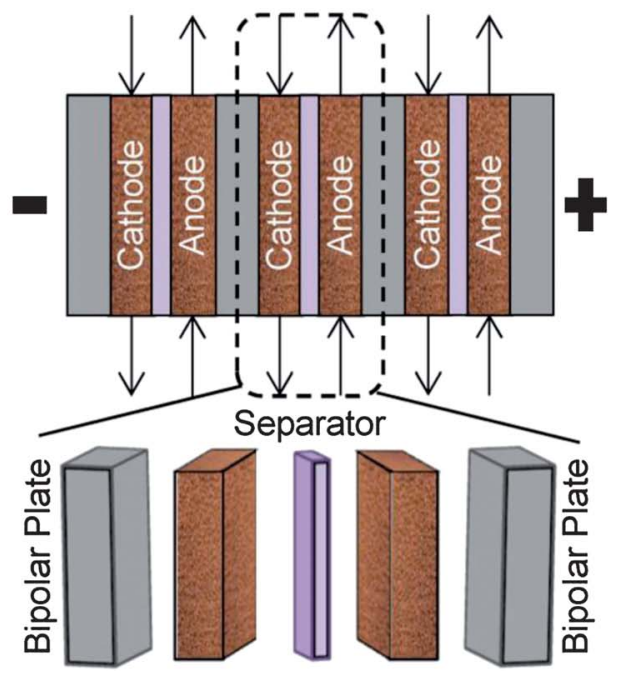

Fig. 1 (a) EMAR $\mathrm{CO}_{2}$ separation cycle for EDA and copper. (b) Schematic diagram of the EMAR $\mathrm{CO}_{2}$ scrubbing process. (c) A cross-sectional view of the EMAR electrochemical cell stack.

Here, Am represents a generic amine molecule and $m$ is the number of $\mathrm{CO}_{2}$ molecules captured per sorbent molecule, equal to the number of amine functional groups in the sorbent molecule divided by 2. The formation of bicarbonate is neglected due to the significant preference for carbamate formation by the primary and secondary amines. The two thermodynamic parameters that define the three reactions (of which only two are linearly independent) are the $\mathrm{CO}_{2}$ binding constant of the first reaction, $K_{\mathrm{CO}_{2}}$, and the stability constant of the amine complexation of the third reaction, $\beta$. These parameters are defined as,

$$
\begin{gathered}
K_{\mathrm{CO}_{2}}=\frac{\left[\mathrm{Am}\left(\mathrm{CO}_{2}\right)_{m}\right]}{[\mathrm{Am}]}\left(\frac{P_{0}}{P_{\mathrm{CO}_{2}}}\right)^{m} \\
\beta=\frac{\left[\mathrm{CuAm}_{2 / m}{ }^{2+}\right]\left[C_{0}\right]^{2 / m}}{\left[\mathrm{Cu}^{2+}\right][\mathrm{Am}]^{2 / m}}
\end{gathered}
$$

respectively, where unit activity coefficients are assumed. In these equations, $P_{0}$ and $C_{0}$ represent standard state pressure and concentration, respectively. By combining the Nernst equation for copper oxidation,

$$
E=E^{0}+\frac{R T}{2 F} \ln \left(\frac{\mathrm{Cu}^{2+}}{C_{0}}\right)
$$

with the mass action equations represented by eqn (2) and (3), we can calculate the open-circuit potentials as a function of the pressure. In eqn (4), $E^{0}$ is the standard state potential of the copper/cupric ion redox couple in the absence of amines or other complexation agents. When the amine complexation with copper (eqn (3)), and the $\mathrm{CO}_{2}$ complexation with the amine (eqn (2)) are included, we obtain

$$
\begin{aligned}
E= & E^{0}+\frac{R T}{2 F}\left[\ln \left(\frac{\mathrm{Cu}_{0}^{2+}}{C_{0}}\right)\right. \\
& \left.-\ln \left(1+\frac{\beta}{C_{0}^{2 / m}}\left[\frac{\mathrm{Am}_{0}-(2 / m) \mathrm{Cu}_{0}^{2+}}{1+K_{\mathrm{CO}_{2}}\left(P_{\left.\mathrm{CO}_{2} / P_{0}\right)^{m}}\right.}\right]^{\frac{2}{m}}\right)\right]
\end{aligned}
$$

where $\mathrm{Cu}_{0}{ }^{2+}$ and $\mathrm{Am}_{0}$ are the total concentrations of cupric ion and amine species, respectively. The open-circuit potential difference between anodic conditions with a $\mathrm{CO}_{2}$ partial pressure of $P_{\mathrm{A}}$ and cathodic conditions with no $\mathrm{CO}_{2}$ present is obtained as the difference between the two corresponding potentials given by eqn (5) with the appropriate pressures. If the solutions in the anode and cathode chambers have the same total cupric ion and amine concentrations, the difference in open-circuit potential can be represented by

$$
\Delta E=E_{\text {anode }}-E_{\text {cathode }}=\frac{R T}{m F} \ln \left(1+K_{\mathrm{CO}_{2}}\left[P_{\mathrm{A}} / P_{0}\right]^{m}\right)
$$

where it has been assumed that $\beta \gg\left(K_{\mathrm{CO}_{2}}\right)^{2 / m}$. Thus, the potential difference is solely a function of the $\mathrm{CO}_{2}$ partial pressure, $P_{\mathrm{A}}$, and the binding constant. Since values for the stability constant are greater than $10^{18}$ for these polyamines, this assumption is valid. ${ }^{41,42}$

To convert the potential difference calculated in eqn (6) to the work of separation per mole of $\mathrm{CO}_{2}$, the charge required to separate one mole of $\mathrm{CO}_{2}$ must be calculated. Based on the reactions shown in eqn (1), one electron is required per molecule of $\mathrm{CO}_{2}$, but, at equilibrium with finite values for $K_{\mathrm{CO}_{2}}$, not all amine molecules entering the anode will be complexed with $\mathrm{CO}_{2}$.

The $\mathrm{CO}_{2}$ loading fraction, $x_{\mathrm{c}}$, can be calculated through rearrangement of eqn (2) and inclusion of a mass balance: 


$$
x_{\mathrm{c}}=\frac{K_{\mathrm{CO}_{2}} P_{\mathrm{F}}{ }^{m}}{P_{0}{ }^{m}+K_{\mathrm{CO}_{2}} P_{\mathrm{F}}{ }^{m}}
$$

where $P_{\mathrm{F}}$ is the flue gas partial pressure of $\mathrm{CO}_{2}$.

An additional inefficiency is caused by the physical solubility of $\mathrm{CO}_{2}$ in the aqueous solution. Since the partial pressure of $\mathrm{CO}_{2}$ in the anode may be considerably higher than the partial pressure in the absorber, some $\mathrm{CO}_{2}$ will be retained in the solution even after the addition of cupric ions. The fraction of chemically bound $\mathrm{CO}_{2}$ that is retained after desorption, $x_{\mathrm{p}}$, can be calculated in terms of the Henry's coefficient, $H_{\mathrm{CO}_{2}}$ (ref. 43) and the molar volume of the solution, $v_{\mathrm{m}}$ :

$$
x_{\mathrm{p}}=\frac{1}{m} \frac{P_{\mathrm{A}}-P_{\mathrm{F}}}{H_{\mathrm{CO}_{2}} v_{\mathrm{m}} x_{\mathrm{c}} \mathrm{Am}_{0}}
$$

This inefficiency could be alleviated by a two-stage flash where the physically bound $\mathrm{CO}_{2}$ is released in the second flash at atmospheric pressure. However, this would necessitate repressurizing the sorbent before sending it back to the cathode to avoid large pressure differences across the membrane.

By allowing for the inefficiencies caused by the incomplete conversion of amines at equilibrium in the absorber and the physical solubility of $\mathrm{CO}_{2}$ in the aqueous solution, we can calculate the open-circuit work of separation of the EMAR system using

$$
W_{\mathrm{CO}_{2}}=\frac{1}{x_{\mathrm{c}}\left(1-x_{\mathrm{p}}\right)} \frac{R T}{m} \ln \left(1+K_{\mathrm{CO}_{2}}\left[P_{\mathrm{A}} / P_{0}\right]^{m}\right)
$$

The thermodynamic efficiency of the process, $\varepsilon_{\text {rev }}$, obtained from the thermodynamically reversible work for a perfect separation divided by the actual work, is then given by

$$
\begin{aligned}
\varepsilon_{\mathrm{rev}}= & \left(\frac{K_{\mathrm{CO}_{2}} P_{\mathrm{F}}{ }^{m}}{P_{0}{ }^{m}+K_{\mathrm{CO}_{2}} P_{\mathrm{F}}{ }^{m}}-\frac{1}{m} \frac{P_{\mathrm{A}}-P_{\mathrm{F}}}{H_{\mathrm{CO}_{2}} v_{\mathrm{m}} \mathrm{Am}_{0}}\right) \\
& \times \frac{\ln \left(\frac{P_{\mathrm{A}}}{P_{\mathrm{F}}}\right)-\frac{P_{0}-P_{\mathrm{F}}}{P_{\mathrm{F}}} \ln \left(1-P_{\mathrm{F}} / P_{0}\right)}{\frac{1}{m} \ln \left(1+K_{\mathrm{CO}_{2}}\left[P_{\mathrm{A}} / P_{0}\right]^{m}\right)}
\end{aligned}
$$

For large values of $\mathrm{K}_{\mathrm{CO}_{2}}$ and negligible physical solubility, the parameter $m$ cancels out entirely. The inherent irreversibilities of this process, which cause the efficiency in eqn (10) to always be less than unity, are the instantaneous changes in the partial pressure of $\mathrm{CO}_{2}$ between the absorber, the anode, and the cathode.

Fig. 2 shows efficiency as a function of $K_{\mathrm{CO}_{2}}$ for a diamine $(m=1)$ solution at $60{ }^{\circ} \mathrm{C}$ with different anode pressures based on eqn (10) with $\mathrm{Am}_{0}=4 \mathrm{M}$ and a flue gas $\mathrm{CO}_{2}$ partial pressure of 0.15 bar. The best efficiencies are obtained between 8 and 15 bars of pressure in the anode. Pressures beyond 15 bars lower the efficiency because of the increased physical solubility of $\mathrm{CO}_{2}$ under these conditions.

It should be noted that the scheme presented in eqn (1) is a simplified model, which may require modification for certain amines. It neglects the possibility of bicarbonate formation, which is especially important for hindered and tertiary amines. $^{\mathbf{1 4}}$ Amines with a mixture of different primary,

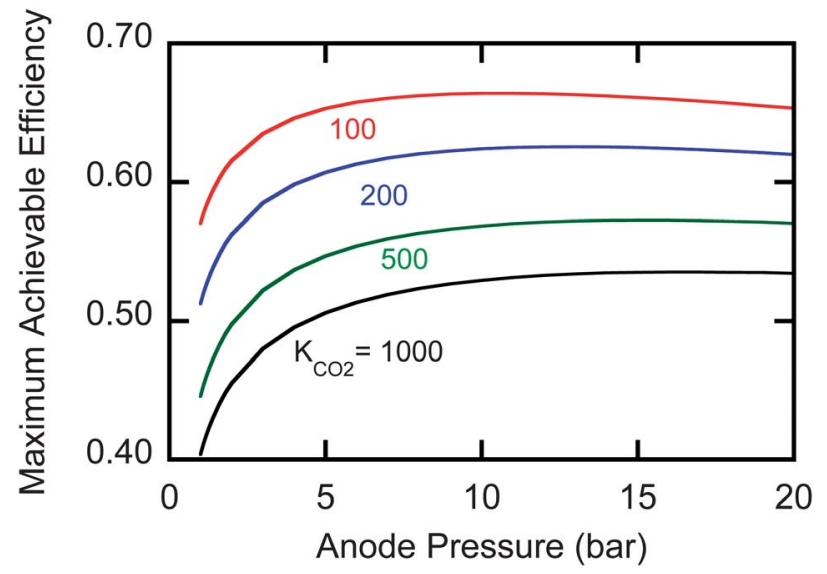

Fig. 2 Maximum efficiencies of an EMAR system at $60^{\circ} \mathrm{C}$ with a diamine sorbent for a range of pressures and $\mathrm{CO}_{2}$ binding constants.

secondary, or tertiary amine groups would also have a more complex reaction scheme including multiple $\mathrm{CO}_{2}$ containing adducts. Some amines, like amino acids salts, possess nonamine functional groups that can interact with the cupric ions to form different complexes. ${ }^{\mathbf{4 4}}$

The formalism in eqn (10), however, is convenient for demonstrating calculation of the maximum achievable efficiencies of the system in terms of fundamental thermodynamic parameters and will be used to model the EDA process. This approach could be applied to any scheme, though a closed-form solution may not be possible for more complicated reaction sequences. For AEEA, DETA, and TETA, the work of $\mathrm{CO}_{2}$ capture will be calculated with the more empirical formula:

$$
W_{\mathrm{CO}_{2}}=\frac{F\langle E\rangle}{x_{\mathrm{c}}\left(1-x_{\mathrm{p}}\right)}=\frac{F\langle E\rangle}{\left(x_{\mathrm{c}}-\frac{1}{m} \frac{P_{\mathrm{A}}-P_{\mathrm{F}}}{H_{\mathrm{CO}_{2}} v_{\mathrm{m}} \mathrm{Am}_{0}}\right)}
$$

The thermodynamic efficiency, with respect to complete separation of the stream, is then given by,

$$
\begin{aligned}
\varepsilon_{\mathrm{rev}}= & \frac{R T}{F\langle\Delta E\rangle}\left(x_{\mathrm{c}}-\frac{1}{m} \frac{P_{\mathrm{A}}-P_{\mathrm{F}}}{H_{\mathrm{CO}_{2}} v_{\mathrm{m}} \mathrm{Am}_{0}}\right) \\
& \times\left(\ln \left(\frac{P_{\mathrm{A}}}{P_{\mathrm{F}}}\right)-\frac{P_{0}-P_{\mathrm{F}}}{P_{\mathrm{F}}} \ln \left(1-P_{\mathrm{F}} / P_{0}\right)\right)
\end{aligned}
$$

As will be shown, $x_{\mathrm{c}}$ and the average potential difference, $\langle\Delta E\rangle$, can be measured experimentally to determine the maximum achievable efficiencies for any amine under a given set of conditions.

\section{Amine utilization}

An important advantage of the EMAR system is its high amine utilization, $U_{\mathrm{A}}$, which is the fraction of amines that are used in each cycle around the system based on a carbamate mechanism, i.e., one molecule of $\mathrm{CO}_{2}$ per two amine functional groups: 


$$
U_{\mathrm{A}}=\frac{1}{m} \frac{n_{\mathrm{CO}_{2}}}{\mathrm{Am}_{0} Q}
$$

Here, $n_{\mathrm{CO}_{2}}$ is the molar flow rate of $\mathrm{CO}_{2}$ in the output and $Q$ is the volumetric flow rate of the amine sorbent in the system. Based on previous definitions, the maximum molar flow rate of $\mathrm{CO}_{2}$ can be represented by

$$
n_{\mathrm{CO}_{2}}=x_{\mathrm{c}}\left(1-x_{\mathrm{p}}\right) m Q \mathrm{Am}_{0}
$$

Combining eqn (13), and (14), we find:

$$
U_{\mathrm{A}}=x_{\mathrm{c}}\left(1-x_{\mathrm{p}}\right)
$$

High amine utilization will lead to lower circulation rates and, as a result, lower capital costs for auxiliary equipment. While the typical value for amine utilization for a thermal system is about $0.5,{ }^{45}$ an EMAR process should be capable of reaching a utilization of up to 0.9 .

By inclusion of eqn (7) and (8), the amine utilization can be calculated using known thermodynamic properties and system parameters:

$$
U_{\mathrm{A}}=\frac{K_{\mathrm{CO}_{2}} P_{\mathrm{F}}{ }^{m}}{P_{0}{ }^{m}+K_{\mathrm{CO}_{2}} P_{\mathrm{F}}{ }^{m}}-\frac{1}{m} \frac{P_{\mathrm{A}}-P_{\mathrm{F}}}{H_{\mathrm{CO}_{2}} v_{\mathrm{m}} \mathrm{Am}_{0}}
$$

The amine utilization depends on the $\mathrm{CO}_{2}$ capacity and the work of separation depends on the $\mathrm{CO}_{2}$ capacity and average potential difference. These parameters vary with the chosen amine and are strong functions of temperature with only a slight dependence on electrolyte composition or pressure. As described below, these parameters have been measured experimentally and the maximum achievable efficiencies at $50{ }^{\circ} \mathrm{C}$ are estimated using eqn (12). The efficiency of an EDA system is also estimated for a wider range of operating conditions using eqn (10) with a temperature dependent function for $K_{\mathrm{CO}_{2}}$ based on its standard state enthalpy and entropy.

\section{Results and discussion}

Fourteen different amines were originally considered for use in the EMAR process, including monoamines, amino acids, and polyamines. The ability of the polyamines to chelate copper ions and form stable copper complexes without the precipitation of salts that plagued the other amine candidates, especially in the presence of $\mathrm{CO}_{2}$, argued for the selection of these polyamines for the EMAR process. The four amines shown in Fig. 3 were deemed the most promising and used for the initial experimental study described in this section.

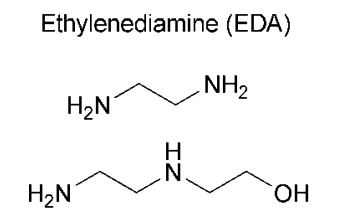

Aminoethylethanolamine (AEEA)

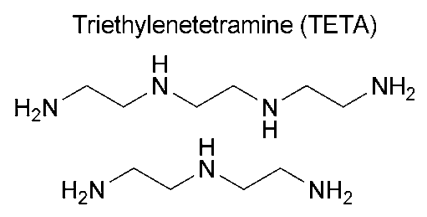

Diethylenetriamine (DETA)
Fig. 3 Structures of tested polyamines.

\section{$\mathrm{CO}_{2}$ capacity measurements}

The $\mathrm{CO}_{2}$ capacities of the four amines were determined at various copper loadings. Based on the assumption that the copper complex formation is significantly stronger than the $\mathrm{CO}_{2}$ binding, the $\mathrm{CO}_{2}$ loading, $\Theta$, defined as the total moles of absorbed $\mathrm{CO}_{2},\left[\mathrm{CO}_{2}\right]_{\text {total }}$, relative to the full capacity of the amines for binding $\mathrm{CO}_{2}, \mathrm{mAm}_{0}$, is expected to be a linear function of the copper loading, $\eta$, i.e.,

$$
\Theta=\frac{x_{\mathrm{c}}}{2}(1-\eta) \quad\left(\Theta=\frac{1}{m} \frac{\left[\mathrm{CO}_{2}\right]_{\text {total }}}{\mathrm{Am}_{0}}, \eta=\frac{2}{m} \frac{\mathrm{Cu}_{0}^{2+}}{\mathrm{Am}_{0}}\right)
$$

The copper loading is defined similarly to the $\mathrm{CO}_{2}$ loading, except that the total capacity of the amines for copper is just half that for $\mathrm{CO}_{2}$. The use of loading, rather than concentration, allows for easier comparison of the behavior of different polyamines. The $\mathrm{CO}_{2}$ loading fraction in the absence of cupric ions, $x_{\mathrm{c}}$, is given by $2 \Theta$ as the copper loading approaches zero.

The $\mathrm{CO}_{2}$ capacity of the different amines as a function of copper loading was measured at $50{ }^{\circ} \mathrm{C}$ using a $15 \% \mathrm{CO}_{2}$ gas mixture; the results shown in Fig. 4 are in excellent agreement with eqn (17) for EDA, TETA, and AEEA. The intercept values for DETA, TETA, and AEEA below 0.5 indicate that the sorbents are not fully loaded with $\mathrm{CO}_{2}$ at $50{ }^{\circ} \mathrm{C}$, i.e., $x_{\mathrm{c}}<1.0$; this incomplete loading can be attributed to the presence of unreacted secondary amine groups. The intercept for EDA, which has no secondary amines, is above 0.5 owing to the formation of a small quantity of bicarbonate, as is commonly observed for primary amines such as MEA. ${ }^{46}$ Of the four amines tested, EDA shows the highest $\mathrm{CO}_{2}$ capacity. The loading of EDA with $\mathrm{CO}_{2}$ as a function of copper loading was also determined at $70{ }^{\circ} \mathrm{C}$; the value of $x_{\mathrm{c}}$ was observed to drop from 1.02 at $50{ }^{\circ} \mathrm{C}$ to 0.92 at 70 ${ }^{\circ} \mathrm{C}$ showing the expected significant temperature dependence of the $\mathrm{CO}_{2}$ reactions with this amine (data not shown). The loading results correspond well with previous literature reports for $\mathrm{EDA}^{36}$ and AEEA, ${ }^{38}$ indicating that the slight differences in conditions from a thermal system, such as the presence of nitrate salts, are inconsequential for $\mathrm{CO}_{2}$ capacities.

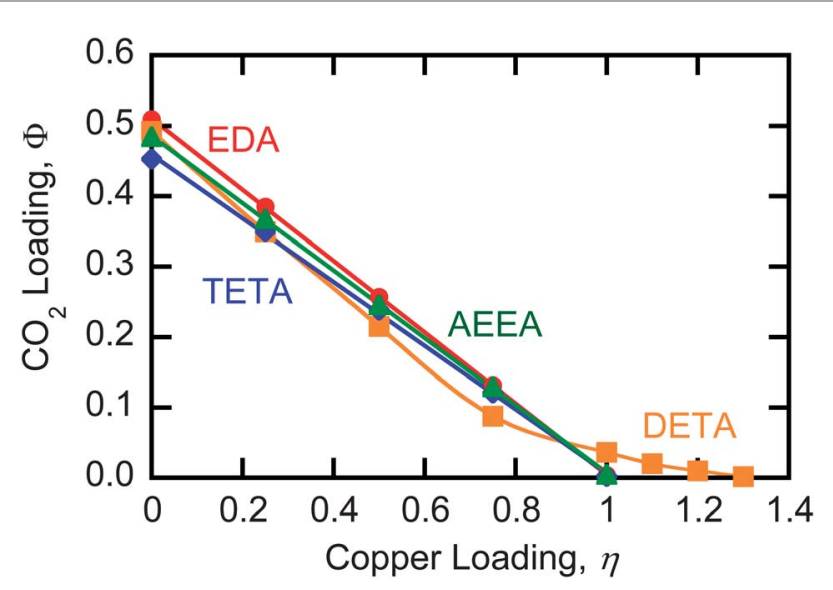

Fig. 4 Equilibrium $\mathrm{CO}_{2}$ capacity data of amine solutions as a function of copper loading at $50{ }^{\circ} \mathrm{C}$ contacted with $15 \% \mathrm{CO}_{2}$ gas stream. Lines are linear fits for EDA, AEEA, and TETA, and a spline for DETA. 
The significant deviation of DETA $\mathrm{CO}_{2}$ loading from eqn (17) suggests that one or more of the assumptions is incorrect for this triamine. Fig. 4 shows that at low loadings, DETA follows a linear trend with a slightly steeper slope than observed with the other amines. Previous studies have shown that at low copper loadings, DETA complexes cupric ions with a $2: 1$ ratio and may interact with up to 6 sites. $^{47,48}$ The presence of $2: 1$ complexes is supported by the breakdown of the linear trend at around $\eta=2 / 3$, which corresponds to a $2: 1$ ratio of DETA to $\mathrm{Cu}^{2+}$ molecules. The slope of the DETA curve at low loadings indicates that each cupric ion disrupts the $\mathrm{CO}_{2}$ absorption of approximately 4.5 amine sites.

At loadings higher than 0.67 , the complexes begin converting from the $2: 1$, where some $\mathrm{CO}_{2}$ affinity remains, to $1: 1$ complexes where the DETA is more tightly bound and no $\mathrm{CO}_{2}$ can be absorbed. At $\eta=4 / 3$, all of the DETA is complexed at the $1: 1$ ratio, which, as can be seen in Fig. 4 , leads to complete $\mathrm{CO}_{2}$ desorption.

\section{UV-Visible spectroscopy}

The ratio of copper to amine species within the complexes under different copper loadings and in the presence and absence of $\mathrm{CO}_{2}$ was investigated by UV-Visible absorbance spectrophotometry. Spectra for the four amines are shown in Fig. 5 under conditions of full copper loading $(\eta=1)$, and excess amine conditions $(\eta<1)$ with and without $\mathrm{CO}_{2}$. For DETA, an additional spectrum is shown where equimolar amounts of cupric ions and DETA are present $(\eta=4 / 3)$. Spectroscopic data are widely available in the literature for amine-copper complexes in the absence of $\mathrm{CO}_{2},{ }^{41,42}$ and show that cupric ions usually interact with four amine functional groups.

For EDA and TETA, the $4: 1$ amine functional group to copper complex is dominant as long as the copper loading is not greater than 1. Upon addition of $\mathrm{CO}_{2}$, no discernible shifts in the spectra occur, confirming the assumption that the copper complexation is significantly more favorable than $\mathrm{CO}_{2}$ binding for EDA and TETA.

For AEEA, the spectrum does vary with copper loading in the absence of $\mathrm{CO}_{2}$ as shown in Fig. 5c. Previous investigations show that at high amine to copper ratios, the alcohol group deprotonates to form different complexes. ${ }^{42}$ When saturated with $\mathrm{CO}_{2}$ or when copper loading equals 1 , the spectra are nearly identical. This indicates that the presence of $\mathrm{CO}_{2}$ causes the formation of the $2: 1$ AEEA to $\mathrm{Cu}^{2+}$ complexes and inhibits deprotonation of the alcohol group, most likely due to the significantly reduced $\mathrm{pH}$ that results from $\mathrm{CO}_{2}$ saturation.

For DETA with excess amine $(\eta=0.4)$, a significant shoulder is observed between 800 and $900 \mathrm{~nm}$ as seen in Fig. 5d. The presence of $\mathrm{CO}_{2}$ causes the disappearance of the shoulder and the corresponding spectrum instead resembles the curve for $\eta=1.3$. This indicates a significant change in the complex being formed and supports the capacity results, which demonstrated the disruption of 4.5 amine sites per cupric ion and not 5 or 6 , which would be expected based on the types of complexes that form in the absence of $\mathrm{CO}_{2} \cdot{ }^{49}$
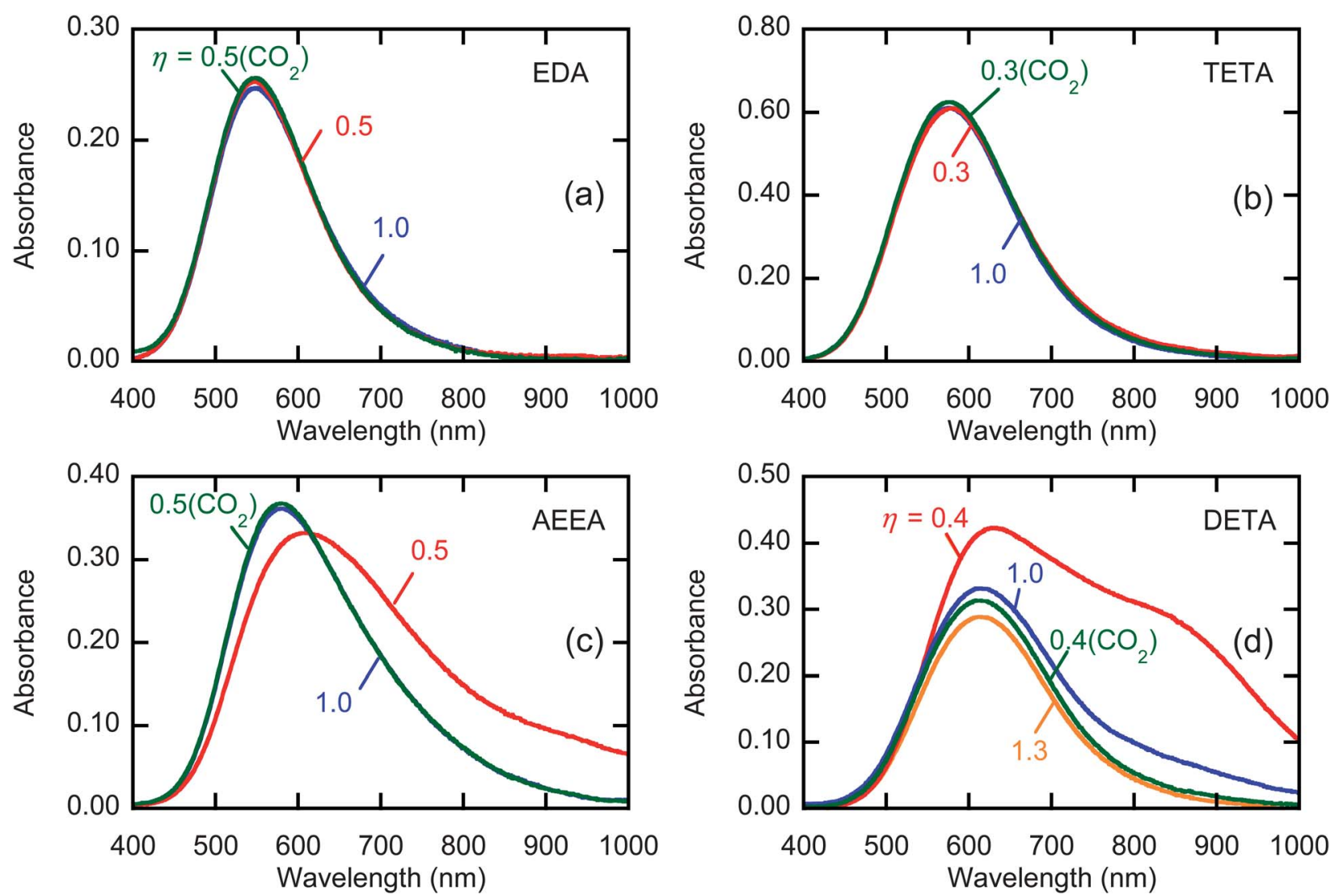

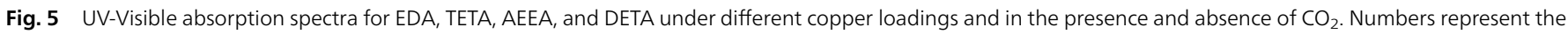
copper loading for each curve. 


\section{Open-circuit potential measurements}

The $\mathrm{CO}_{2}$ capacity measurements demonstrate that the $\mathrm{CO}_{2}$ release can be controlled by modulation of the cupric ion concentration in the solution. Measurements of the open-circuit potential differences between a copper electrode under anodic and cathodic conditions provide an estimate of the energy requirements for cupric ion generation and removal under low flux conditions. We can estimate the efficiency of the separation using eqn (12) with the value of $x_{\mathrm{c}}$ determined in the capacity experiments and the potential difference, $\langle\Delta E\rangle$, obtained from the open-circuit experiments. Inclusion of kinetic overpotentials at the electrodes and Ohmic potential drops in the solution and through the membrane will be considered in future publications.

The open-circuit potentials of a copper electrode in a $1 \mathrm{M}$ EDA solution in $1 \mathrm{M} \mathrm{NaNO}_{3}$ as a function of cupric ion loading under argon are shown in Fig. 6a. Cupric ion concentration was controlled through the addition of cupric nitrate, $\mathrm{Cu}\left(\mathrm{NO}_{3}\right)_{2}$. Essentially the same results were obtained with $\mathrm{NaCl}$ instead of $\mathrm{NaNO}_{3}$ (data not shown). The solid line in Fig. 5a represents the equation

$$
E=E^{0}+\frac{R T}{2 F}\left[\ln \left(\frac{\mathrm{Cu}_{0}{ }^{2+}}{C_{0}}\right)-\ln \left(\beta\left[\frac{\mathrm{Am}_{0}-(2 / m) \mathrm{Cu}_{0}{ }^{2+}}{C_{0}}\right]^{2 / m}\right)\right]
$$

where $\beta$ is the lone fitted parameter. This model equation can be derived readily by combining eqn (3) and (4), and invoking the assumption that $\beta \gg 1$. The standard state is defined as a one molar solution of cupric ions with no amines present. The corresponding value of $E^{0}$ with respect to the $\mathrm{Ag} / \mathrm{AgCl}$ reference electrode $(0.209$ volts $v s$. SHE) is -0.131 volts. Using this model, we determined the value of the stability constant of EDA at $50{ }^{\circ} \mathrm{C}$ to be $1.8 \times 10^{18}$, which agrees well with literature value of $3.0 \times$ $10^{18}$ at $49{ }^{\circ} \mathrm{C}$ estimated from the results of Cotton and Harris. ${ }^{49}$ Eqn (18) provides equally accurate fits to the open-circuit potentials measured under a pure $\mathrm{CO}_{2}$ atmosphere, although the calculated stability constant is reduced to $1.4 \times 10^{12}$ due to the competition between the copper and the $\mathrm{CO}_{2}$ for the amines.

The open-circuit copper potentials of an EDA solution in the presence and absence of $\mathrm{CO}_{2}$ are shown as a function of copper loading in Fig. 6b. These curves represent anodic and cathodic conditions, respectively, of an EMAR process that desorbs at 1 atmosphere. The top $x$-axis shows the state of charge (SOC) of the system, in units of Coulombs, calculated from

$$
\mathrm{SOC}=2 \mathrm{FCu}_{0}{ }^{2+}=m F \mathrm{Am}_{0} \eta
$$

The area between the anodic and cathodic curves based on the SOC $x$-axis equals the work of a single cycle, in direct electrochemical analogy with the well-known cycle areas in PV and TS diagrams. The average potential difference, used in eqn (12), can be obtained from Fig. $6 \mathrm{~b}$ as the average distance between the two curves

$$
\langle\Delta E\rangle=\frac{1}{b-a} \int_{a}^{b}\left(E_{\text {anode }}-E_{\text {cathode }}\right) \mathrm{d}(\text { SOC })
$$
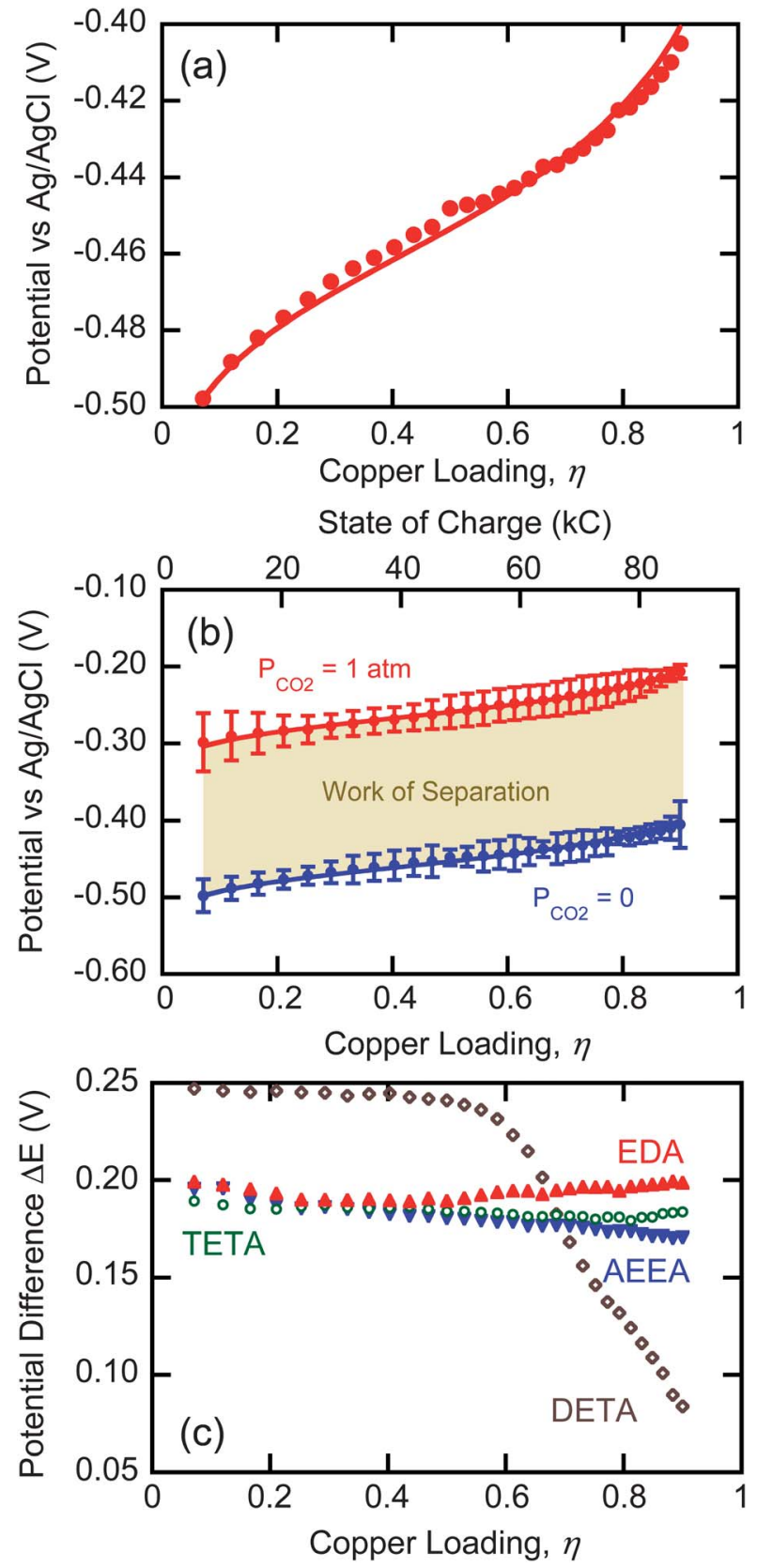

Fig. 6 (a) Open-circuit potentials of an EDA solution under argon as a function of loading. Points represent measured values and the line is fit using eqn (18). (b) Open-circuit potentials of an EDA solution under argon (blue) and $\mathrm{CO}_{2}$ (red). Error bars represent $95 \%$ confidence based on $t$-distribution. (c) Open-circuit potential differences for EDA, TETA, AEEA, and DETA as a function of copper loading.

where $a$ and $b$ represent the extremes of the state of charge in the system.

Fig. $6 c$ shows the differences in anodic and cathodic potentials for the four amines as a function of copper loading. The potential differences for EDA and TETA are relatively constant, and show no clear variations over the copper loading range. AEEA, however, shows a noticeable decrease in the potential difference with increasing copper loading because the $\mathrm{pH}$, and thus the stability constant, decreased in the absence of $\mathrm{CO}_{2}$ but not in its presence. In the presence of $\mathrm{CO}_{2}$, the $\mathrm{pH}$ changes are 
Table 1 Predicted open-circuit performance of an EMAR system using different amines with $1 \mathrm{~atm} \mathrm{CO}_{2}$ desorption and $15 \% \mathrm{CO}_{2}$ flue gas

\begin{tabular}{llllll}
\hline Amine & $x_{\mathrm{c}}{ }^{a}$ & $x_{\mathrm{p}}$ & $\langle\Delta E\rangle^{b}$ & $W_{\mathrm{CO}_{2}{ }^{c}}$ & ${ }^{{ }^{d}{ }_{\mathrm{rev}}}$ \\
\hline EDA $\left(70{ }^{\circ} \mathrm{C}\right)$ & $0.93 \pm 0.03$ & 0.003 & 0.142 & 14.7 & 0.54 \\
EDA $\left(50^{\circ} \mathrm{C}\right)$ & $1.02 \pm 0.01$ & 0.004 & 0.194 & 18.4 & 0.41 \\
AEEA $\left(50^{\circ} \mathrm{C}\right)$ & $0.98 \pm 0.01$ & 0.004 & 0.180 & 17.9 & 0.42 \\
TETA $\left(50^{\circ} \mathrm{C}\right)$ & $0.92 \pm 0.02$ & 0.005 & 0.183 & 19.2 & 0.39 \\
DETA $\left(50^{\circ} \mathrm{C}\right)^{e}$ & $1.08 \pm 0.09$ & 0.004 & 0.238 & 21.4 & 0.35
\end{tabular}

${ }^{a}$ Calculated from eqn (17). ${ }^{b}$ In units of volts. ${ }^{c}$ Calculated from eqn (11) in units of kJ per mole. ${ }^{d}$ Calculated from eqn (12). ${ }^{e}$ For $\eta$ equals 0 to 0.67 .

negligible because of the buffering ability of the carbamates. By contrast, pH changes do not affect the stability constants of EDA and TETA since they do not have alcohol groups that can deprotonate. DETA shows a dramatic drop in potential difference at loadings greater than 0.67 owing to the previously discussed transition from a $2: 1$ DETA to $\mathrm{Cu}^{2+}$ binding regime, where $\mathrm{CO}_{2}$ has a dramatic effect on the copper complex, to the 1:1 binding regime, where the presence of $\mathrm{CO}_{2}$ is less impactful.

The efficiency of an open-circuit EMAR process is tabulated in Table 1 for each of the four amines at $50^{\circ} \mathrm{C}$, and for EDA at 70 ${ }^{\circ} \mathrm{C}$. The tabulated efficiencies were calculated from eqn (12) with parameters estimated experimentally through eqn (17) and (20), and under the assumption of desorption at 1 atmosphere of pressure and absorption from a $15 \% \mathrm{CO}_{2}$ flue gas. The efficiency is based on removal of $100 \%$ of the $\mathrm{CO}_{2}$ from the flue gas.

Table 1 shows that at $70{ }^{\circ} \mathrm{C}$, an EMAR system using EDA as the amine sorbent should be able to achieve 54\% efficiency under open-circuit conditions. This represents a work of separation, $W_{\mathrm{CO}_{2}}$, of $15 \mathrm{~kJ}$ per mole as calculated by eqn (11). At lower temperatures, the efficiency drops to $41 \%$ and is relatively similar for EDA, AEEA, and TETA, ranging from 39\% to $42 \%$. The efficiency loss due to the physical solubility of the $\mathrm{CO}_{2}$ is negligible in every case because of the low desorption pressure. While the absorption capacity for $\mathrm{CO}_{2}$ does drop by about $10 \%$ at the higher temperature for EDA, the open-circuit potential required drops by $20 \%$, making the higher temperature more efficient. The importance of operating temperature is highlighted clearly by Table 1 ; to obtain estimates of efficiency for a wider range of conditions, we will combine eqn (10) with the temperature dependence of $K_{\mathrm{CO}_{2}}$ for EDA.

\section{Analysis of EDA thermodynamics}

With the aid of eqn (4), it is possible to relate the open-circuit potential difference to the $\mathrm{CO}_{2}$ binding constant, $K_{\mathrm{CO}_{2}}$, which is sufficient to predict the system-wide efficiency under different absorption and desorption partial pressures. This approach, however, can only be applied rigorously to EDA, which follows the simple reaction mechanism shown in eqn (1) at flue gas conditions. The equilibrium constant can also be used to calculate the free energy of the $\mathrm{CO}_{2}$ absorption reaction via eqn (6), which can be rearranged to give

$$
K_{\mathrm{CO}_{2}}=\left(\mathrm{e}^{\frac{F \Delta E}{R T}}-1\right) \frac{P_{0}}{P_{\mathrm{CO}_{2}}}=\mathrm{e}^{-\Delta G_{\mathrm{rxn}}^{0} / R T}
$$

where it is recognized that, for EDA, $m=1$.

To predict the performance of an EDA system over a range of temperatures, the standard state enthalpies and entropies of reaction must be known. These quantities can be extracted from measurements of the open-circuit potential difference over a range of temperatures. Fig. 7a shows the potential difference values for an EDA system from $50{ }^{\circ} \mathrm{C}$ to $80{ }^{\circ} \mathrm{C}$. If it is assumed that $K_{\mathrm{CO}_{2}} P_{\mathrm{CO}_{2}} / P_{0} \gg 1$, then manipulation of eqn (21) and expression of the free energy in terms of the enthalpy and entropy yields a linear relationship between the potential difference and the temperature at constant pressure:

$$
\Delta E=\frac{R T}{F} \ln \left(\frac{P_{\mathrm{CO}_{2}}}{P_{0}}\right)-\frac{\Delta G_{\mathrm{CO}_{2}}^{0}}{F}=\frac{R T}{F} \ln \left(\frac{P_{\mathrm{CO}_{2}}}{P_{0}}\right)-\frac{\Delta H^{0}}{F}+T \frac{\Delta S^{0}}{F}
$$

Assuming the standard state enthalpy and entropy are not functions of temperature, we can differentiate all terms with respect to temperature:

$$
\frac{\mathrm{d} \Delta E}{\mathrm{~d} T}=\frac{\Delta S^{0}}{F}+\frac{R}{F} \ln \left(\frac{P_{\mathrm{CO}_{2}}}{P_{0}}\right)
$$

Thus, at constant pressure, the entropy can be estimated from

$$
\Delta S^{0}=F \frac{\mathrm{d} \Delta E}{\mathrm{~d} T}-R \ln \left(\frac{P_{\mathrm{CO}_{2}}}{P_{0}}\right)
$$

where the value of the derivative is obtained by linear regression of the data in Fig. 7a. The enthalpy can then be calculated in terms of this derivative and the potential difference itself via

$$
\Delta H^{0}=F T \frac{\mathrm{d} \Delta E}{\mathrm{~d} T}-F \Delta E
$$

Combined with the data in Fig. 7a and eqn (25) yields an enthalpy of sorption of $86.4 \pm 1.1 \mathrm{~kJ}$ per mole $\mathrm{CO}_{2}$, which agrees with data reported by Zhou et al. ${ }^{36}$

Using these experimentally determined thermodynamic parameters, we can estimate $K_{\mathrm{CO}_{2}}$ over the relevant operational range of temperatures (see Fig. 7b), and use these values with eqn (10) to predict efficiencies at $50{ }^{\circ} \mathrm{C}$ and $70{ }^{\circ} \mathrm{C}$, the temperatures at which experimental data are reported in Table 1 . The calculated efficiencies are 0.41 at $50{ }^{\circ} \mathrm{C}$ and 0.54 at $70{ }^{\circ} \mathrm{C}$ in excellent agreement with the measured values. These results demonstrate that this model can effectively predict performance over the relevant operational range for EDA. The model does not rely on the absorption capacity measurements previously used to calculate $x_{\mathrm{c}}$ but instead uses the predicted values of $K_{\mathrm{CO}_{2}}$ to calculate $x_{\mathrm{c}}$ through eqn (7). The ability to predict $K_{\mathrm{CO}_{2}}$ allows the calculation of efficiency under any set of flue gas conditions, electrochemical cell temperature, and desorption pressure based on simple and inexpensive electrochemical experiments.

This represents the first time copper activity measurements have been used for calculation of amine $/ \mathrm{CO}_{2}$ sorption equilibria 

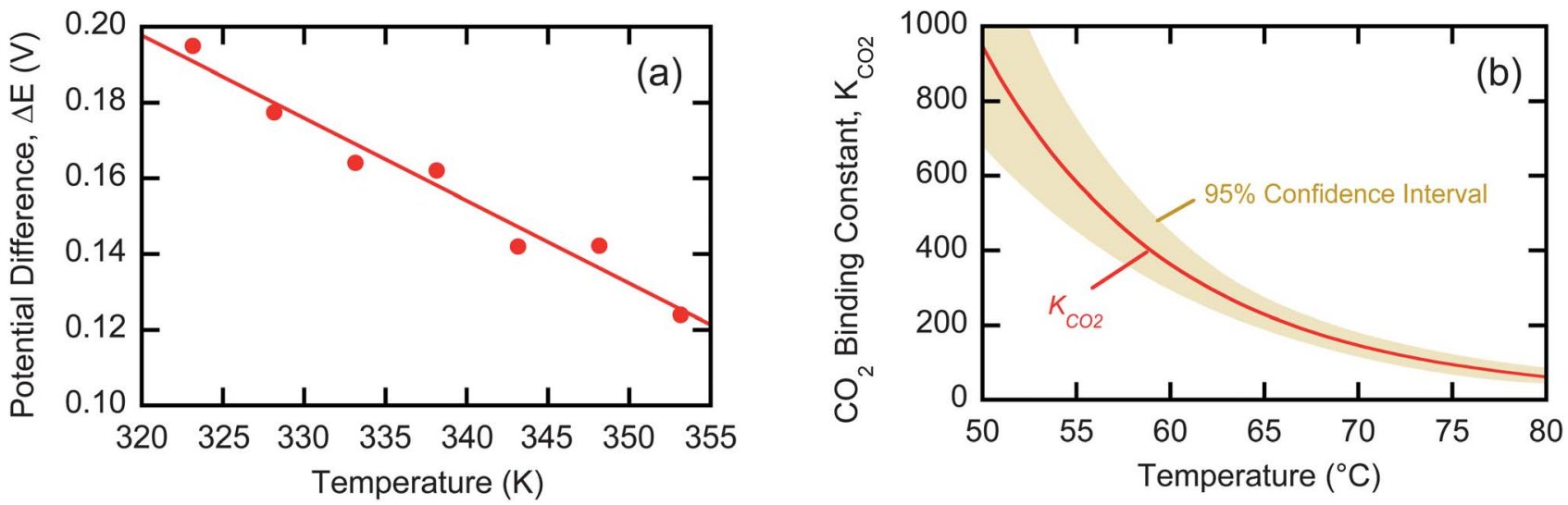

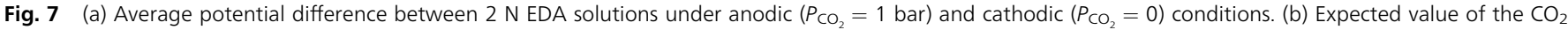
binding coefficient for EDA as a function of temperature. Tan area represents the $95 \%$ confidence interval based on $t$-distribution.

and the corresponding thermodynamic parameters. These copper activity measurements, which are significantly cheaper and easier to run than are alternative methods, provide slightly different information than obtained from traditional barium salt titrations, for instance, which measure the total dissolved $\mathrm{CO}_{2}$, whereas the copper activity indicates the fraction of uncomplexed amines. In many cases this information will be analogous; however, there may be some cases where a combination of the two methods can lead to an improved understanding of the $\mathrm{CO}_{2}$ complexed species.

\section{Optimal operating conditions for EMAR with EDA}

With the model developed in eqn (10) and the experimentally determined thermodynamic parameters for $K_{\mathrm{CO}_{2}}$, the EDA system efficiency can be calculated for a wide range of temperatures, desorption pressures, and flue gas compositions. Fig. 8 shows the efficiency from $50{ }^{\circ} \mathrm{C}$ to $80^{\circ} \mathrm{C}$ and from 1 to 18 bar of desorption pressure for a $15 \% \mathrm{CO}_{2}$ flue gas.

While the efficiency will be lowered by kinetic losses and auxiliary equipment power demands, initial efficiencies, with

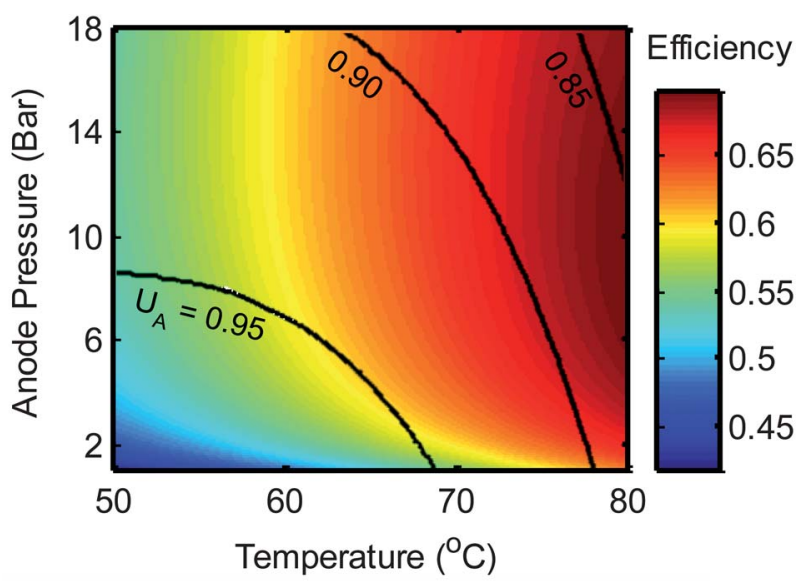

Fig. 8 Open-circuit efficiency of the EMAR system based on experimentally derived $K_{\mathrm{CO}_{2}}$ values and eqn (10). Black lines are contours of amine utilization, $U_{\mathrm{A}}$ from eqn (16). an amine utilization of 0.9 , of $69 \%$ at 8 bars and $76{ }^{\circ} \mathrm{C}$ and $63 \%$ at atmospheric pressure and $80{ }^{\circ} \mathrm{C}$ are encouraging. Even lower voltage requirements could be achieved through heating of the electrochemical cell with any $>80{ }^{\circ} \mathrm{C}$ waste heat that might be available. A comparable MEA process would have a theoretical efficiency of $62 \%$ assuming absorption at $60{ }^{\circ} \mathrm{C}$ and regeneration at $120{ }^{\circ} \mathrm{C}$.

\section{Bench scale operation}

A bench scale EMAR setup including each element shown in Fig. 2 was constructed and tested. The system had $100 \mathrm{~cm}^{2}$ of membrane area separating two $0.8 \mathrm{~mm}$ thick chambers with flat copper electrodes serving as the chamber walls. Fig. 9 shows a schematic diagram of the experimental setup. Pure $\mathrm{CO}_{2}$ was passed through the absorber during operation to ensure complete saturation of the amines. A lower concentration of $\mathrm{CO}_{2}$ fed to the absorber would lead to significant inefficiencies in the overall process due to physical solubility differences between the absorber and the anode. In a larger system, where the swing in copper loading is greater, operating at higher temperatures, which reduces physical solubility, the inefficiency due to physical solubility would most likely be negligible, so the use of 100 percent $\mathrm{CO}_{2}$ should not cause misleading results.

The output gas from the anode was taken with a nitrogen sweep stream to a GC to measure the composition, from which the $\mathrm{CO}_{2}$ generation rate was calculated. The Faradaic efficiency

$$
\varepsilon_{\mathrm{F}}=\frac{n_{\mathrm{CO}_{2}}}{I F}
$$

represents the fraction of electrons that release $\mathrm{CO}_{2}$ through the EMAR cycle. Here $n_{\mathrm{CO}_{2}}$, is the molar flow rate of $\mathrm{CO}_{2}$ from the anode and $I$ is the applied current. The primary reason for current efficiencies below unity is crossover of $\mathrm{CO}_{2}$ and other species between the chambers through the membrane.

Results from a 5 hour bench scale experiment are shown in Fig. 10. At a current of $0.25 \mathrm{~A}\left(25 \mathrm{~A} \mathrm{~m}^{-2}\right)$, the $\mathrm{CO}_{2}$ output of the system increased by $1.6 \mathrm{~mL} \mathrm{~min}^{-1}$, corresponding to a Faradaic efficiency of $42 \%$. A thorough investigation of the sources of this inefficiency is underway and will be presented in future 


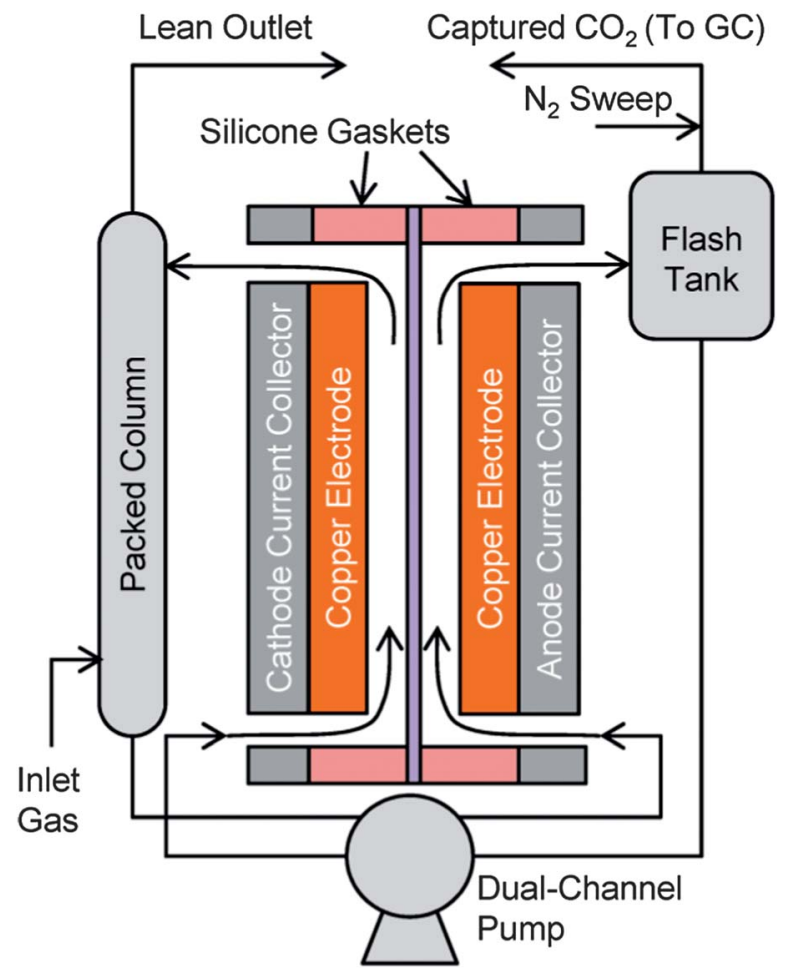

Fig. 9 Schematic diagram of bench-scale EMAR system.

communications. The second $y$-axis in Fig. 10 shows the potential difference across the cell. The voltage dropped from about 0.5 to $0.4 \mathrm{~V}$ over the course of the experiment, presumably because of changes on the electrode surface that occurred during the experiment. The open-circuit potential of the system, which was estimated by the potential obtained immediately after the current was disconnected, was 0.17 volts. Combining the required voltage with the Faradaic efficiency, we estimated that the system energy requirement was $94.2 \mathrm{~kJ}$ per mole $\mathrm{CO}_{2}$, corresponding to an energy efficiency of $18 \%$ with respect to an open-circuit system with $100 \%$ Faradaic efficiency; with optimization of the system, significantly higher efficiencies can be anticipated.

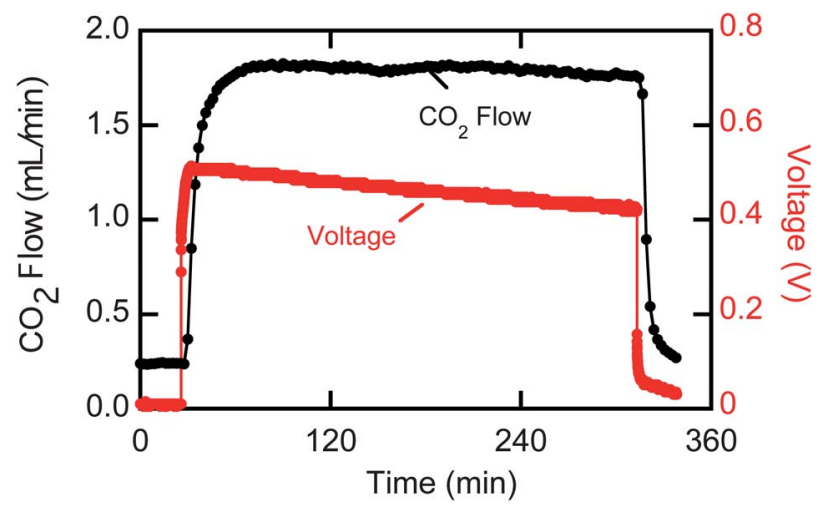

Fig. $10 \mathrm{CO}_{2}$ output and voltage results from a bench scale EMAR system operating at $0.25 \mathrm{~A}$ with EDA at room temperature.
Incorporation of porous electrodes, operation at higher temperature, and an increase in the electrolyte concentration will all improve efficiency. Use of ion selective membranes, especially anion exchange membranes, would significantly reduce the unwanted diffusion and migration across the membrane leading to higher Faradaic efficiencies. Increasing the current may also improve efficiency; Eisaman et al. reported current efficiencies that doubled when they increased the currents density from $50 \mathrm{~A} \mathrm{~m}^{-2}$ to $200 \mathrm{~A} \mathrm{~m}^{-2}$ in their electrodialysis based $\mathrm{CO}_{2}$ capture system. ${ }^{32}$ In previous studies, electrochemically modulated complexation gas separations have been reported to operate at low efficiencies. ${ }^{35}$ Terry et al., for instance, recorded efficiencies below $1 \%$ in their work on the concentration of carbon monoxide by electrochemical means. ${ }^{28}$

\section{Advantages of an EMAR system}

The high amine utilization, expected to be at least 0.9 based on Fig. 8, corresponds to low lean loadings entering the absorber. Using "thick-film theory", Meldon shows that the enhancement factor, $E_{\mathrm{f}}$, which is proportional to the rate of absorption, is roughly proportional to the square root of the unreacted amine concentration, $x_{\mathrm{AM}} \cdot{ }^{50}$ The fraction of unreacted amines entering the absorber is less than unity due to the physical solubility of $\mathrm{CO}_{2}$ under the high pressure conditions in the anode. Therefore,

$$
x_{\mathrm{AM}}=1-x_{\mathrm{p}}
$$

An average enhancement factor for the absorber can be estimated by integration of the local enhancement factor over the column, from the initial lean loading condition to the final condition at which there is negligible remaining free amine; the resulting equation is

$$
\left\langle E_{\mathrm{f}}\right\rangle=\frac{1}{0-x_{\mathrm{AM}}} \int_{x_{\mathrm{AM}}}^{0} E_{\mathrm{f}}(x) \mathrm{d} x=\frac{1}{x_{\mathrm{AM}}} \int_{0}^{x_{\mathrm{AM}}} \sqrt{x \mathrm{~d} x}=\frac{2}{3} \sqrt{x_{\mathrm{AM}}}
$$

This result indicates that an EMAR system with a lean loading of $98 \%$ of the maximum should demonstrate a $40 \%$ increase in absorption rate over a thermal system where the initial free amine loading is only $50 \%$ of the maximum. The viscosity of the amine solution in the absorber would not be significantly different from that in a thermal system because the temperatures would be nearly the same and the copper ion concentration in the sorbent in the absorber would be small.

Absorber size reduction in conjunction with the removal of the first half of the compression train will dramatically reduce the capital expenses, and, therefore, the cost of electricity of an EMAR system compared to a traditional thermal scrubbing setup.

Lower desorption temperatures will reduce the thermal degradation of the amines, although oxidative degradation will still occur. Dissolved oxygen in the sorbent solution may also lead to oxidation of the copper electrodes. Their oxidative degradation is expected to be minimal, however, due to the low solubility of oxygen in water under the projected operating conditions, but does need to be investigated and quantified in future studies. 


\section{EDA as a $\mathrm{CO}_{2}$ capture sorbent}

EDA has been considered in the past for use as the $\mathrm{CO}_{2}$ sorbent in thermal scrubbing systems as it possesses several attractive qualities including high $\mathrm{CO}_{2}$ capacity, low cost, fast kinetics, and low viscosities even in concentrated solutions saturated with $\mathrm{CO}_{2} \cdot{ }^{36}$ Pilot tests performed with EDA, however, determined that the steam required for regeneration was too high for an economically viable process. ${ }^{37}$

The high desorption energy requirements of EDA compared to MEA, which contains similar functional groups, results from the strong temperature and $\mathrm{CO}_{2}$ loading dependence of the enthalpy of sorption. ${ }^{36}$ As the temperature increases, the heat of $\mathrm{CO}_{2}$ absorption increases, while with decreases in $\mathrm{CO}_{2}$ loading, the enthalpy of sorption increases sharply. One possible explanation for these effects could be the transition from the reaction

$$
\mathrm{H}_{2} \mathrm{NCH}_{2} \mathrm{CH}_{2} \mathrm{NH}_{2}+\mathrm{CO}_{2} \rightleftharpoons \mathrm{H}_{3} \mathrm{NCH}_{2} \mathrm{CH}_{2} \mathrm{NHCO}_{2}
$$

which would occur at high loadings of $\mathrm{CO}_{2}$, to the reaction

$$
\begin{aligned}
2 \mathrm{H}_{2} \mathrm{NCH}_{2} \mathrm{CH}_{2} \mathrm{NH}_{2}+\mathrm{CO}_{2} \rightleftharpoons & \mathrm{H}_{2} \mathrm{NCH}_{2} \mathrm{CH}_{2} \mathrm{NH}_{3}{ }^{+} \\
& +\mathrm{H}_{2} \mathrm{NCH}_{2} \mathrm{CH}_{2} \mathrm{NHCO}_{2}^{-}
\end{aligned}
$$

which would occur when the solution has a low loading of $\mathrm{CO}_{2}$. In a thermal system, this dual reaction scheme leads to a large steam requirement in the stripper where the enthalpy is elevated due to the high temperatures and low loading.

For the EMAR process, conversely, the temperature is consistently low and the effective loading of the amines is kept high in the anode. While the total $\mathrm{CO}_{2}$ loading in the anode does decrease through the addition of cupric ions, the amines in the anode that are not complexed by the copper retain a high loading of $\mathrm{CO}_{2}$; i.e., the reaction in eqn (29) will be dominant because the concentration of uncomplexed EDA molecules will be very low. Therefore, the enthalpy of sorption should remain low in the anode of the electrochemical cell. By operating under conditions where the enthalpy of sorption remains low, the electrical regeneration of EDA should be more efficient than the thermal regeneration process.

\section{Experimental}

\section{Materials}

Solutions were prepared with distilled and deionized $18 \mathrm{M} \Omega \mathrm{cm}$ water using a Milli-Q system. All chemicals used were purchased from Sigma-Aldrich. Background electrolytes used were sodium nitrate $\left(\mathrm{NaNO}_{3}\right.$, purity $\left.>99 \%\right)$ and potassium nitrate $\left(\mathrm{KNO}_{3}\right.$, purity $\left.>99 \%\right)$. Cupric ions were added to solutions through the addition of copper nitrate semi(pentahydrate) $\left(\mathrm{Cu}\left(\mathrm{NO}_{3}\right)_{2}\right.$, purity $\left.>98 \%\right)$. All amines used were of at least $99 \%$ purity. For TETA, which was purchased as a solid hydrate, the supplier-provided Karl-Fischer titration data were used to determine the true molecular weight of the hydrated complex.

$\mathrm{Ag} / \mathrm{AgCl}$ reference electrodes were purchased through BASi (West Lafayette, IN). Copper 101 alloy (purity >99.99\%) was used for the copper plate electrodes and the copper wire. The membrane used for the bench-scale setup was a Celgard ${ }^{\circledR} 3501$ surfactant-coated porous polypropylene membrane.

\section{$\mathrm{CO}_{2}$ capacity measurements}

All solutions tested were $2 \mathrm{~N}$ amine solutions (with normality referring to the number of amine functional groups) with $1 \mathrm{M}$ $\mathrm{KNO}_{3}$. A $15 \% \mathrm{CO}_{2}$ in nitrogen mixture was bubbled through the solutions with vigorous stirring at a constant flow rate. The outlet concentration, which was quantified by gas chromatography (Varian CP-3800), was used to calculate the rate of absorption by the solution. The measured rates were integrated over the time of the experiment to determine the total solution capacity. The reported values were corrected by subtracting the measured absorption of a $1 \mathrm{M}$ potassium nitrate solution with no amines to account for dead volume associated with the head space in the flask, the tubing volume, and the like.

\section{Open-circuit potential measurements}

All solutions tested were $2 \mathrm{~N}$ amine solutions with $1 \mathrm{M} \mathrm{NaNO}_{3}$. The open-circuit potentials were measured with a copper wire working electrode and a $\mathrm{Ag} / \mathrm{AgCl}$ reference electrode. The initial solutions contained $10 \mathrm{mM}$ of $\mathrm{Cu}\left(\mathrm{NO}_{3}\right)_{2}$. Measurements spanning the range of copper loadings with constant amine concentration were performed by repeated injections of equal amounts of a $4 \mathrm{~N}$ amine and $2 \mathrm{M} \mathrm{NaNO}_{3}$ solution and a $2 \mathrm{M} \mathrm{Cu}\left(\mathrm{NO}_{3}\right)_{2}$ solution followed by a measurement for each new composition. For measurements representing cathodic conditions, the system was kept under argon and an equilibration time of 60 seconds was given between injections. For measurements representing anodic conditions, the system was kept under pure $\mathrm{CO}_{2}$ at atmospheric pressure and 240 seconds of equilibration time was given between injections. The solutions were gently stirred at all times. Temperature was controlled by submerging the electrochemical cell in a temperature controlled oil bath. Electrochemical experiments were performed on a VersaStat 3 potentiostat from Princeton Applied Research.

\section{UV-Visible spectroscopy measurements}

The UV-Visible absorbance solutions with $10 \mathrm{mM} \mathrm{Cu}\left(\mathrm{NO}_{3}\right)_{2}$ and varying amine concentrations ranging from 30 to $120 \mathrm{mN} . \mathrm{CO}_{2}$ saturated solutions were prepared by pre-saturating a concentrated amine solution then diluting it and adding the $\mathrm{Cu}\left(\mathrm{NO}_{3}\right)_{2}$. Measurements were taken with an Evolution 220 spectrophotometer from Thermo-Scientific.

\section{Bench-scale experiments}

Aqueous solutions used in bench scale experiments contained 1 M EDA, $1 \mathrm{M} \mathrm{NaNO}_{3}$, and $0.25 \mathrm{M} \mathrm{Cu}\left(\mathrm{NO}_{3}\right)_{2}$. Solutions were saturated with $\mathrm{CO}_{2}$ by flowing the solution through the system with zero current and passing pure $\mathrm{CO}_{2}$ through the absorber. The saturation with $\mathrm{CO}_{2}$ was continued until the outlet $\mathrm{CO}_{2}$ flow rate from the absorber was constant as measured with a ColeParmer volumetric digital flow meter. The entire system contained $40 \mathrm{~mL}$ of solution, of which, $5 \mathrm{~mL}$ was contained in the electrochemical cell. The absorber was a 24 inch long glass tube 
packed with 316 stainless steel size 10 lock washers. The flash tank was a $25 \mathrm{~mL}$ three neck flask. A $10 \mathrm{sccm}$ nitrogen stream was used as the sweep gas to the GC. The solution was circulated at $10 \mathrm{~mL} \mathrm{~min}^{-1}$ using a dual channel MasterFlex pump.

The flow channels in the electrochemical cells were cut out from silicone gaskets placed on top of the copper plates. The frame of the device was made from aluminum and also acted as the current collectors. Strips of cheesecloth were placed between the copper plate electrodes and the membrane to prevent collapse of the channel.

\section{Conclusion}

An electrochemical method for $\mathrm{CO}_{2}$ desorption and amine regeneration has been presented as an alternative to the traditional thermal swing process. This system offers several advantages over the traditional process including desorption of $\mathrm{CO}_{2}$ at elevated pressures, increased efficiency, reduced absorber size, and improved utilization of the amine per cycle.

As a proof of concept, a bench scale system was constructed and operated to show that $\mathrm{CO}_{2}$ could be captured in an absorber and released in the anode. Current efficiencies of $42 \%$ were achieved when operating at $25 \mathrm{~A} \mathrm{~m}^{-2}$ membrane current density and room temperature. Models show that significantly improved performance, with open-circuit efficiencies near 70\%, can be achieved through operation at elevated temperatures and pressures.

An electrically driven post-combustion system, which is not heavily integrated into the plant with the exception of drawing electricity, possesses distinct operational advantages through increased flexibility. At peak operating times when electricity is at its highest value, the flow through the capture plant could be reduced easily. This allows a plant to operate at a nearly constant electrical output by varying the amount of that electricity that is used for capture based on the highly variable value of electricity.

This system also can be used in plants and factories where lowpressure steam utilities are unavailable. Application to $\mathrm{CO}_{2}$ sources, such as plants for cement, aluminum, or steel, which may be unable to provide low-pressure steam, is possible since the EMAR process can be powered by a distant electrical source. Use for scaled-down processes such as $\mathrm{CO}_{2}$ removal from submarines, space shuttles, or other confined spaces is also feasible.

\section{Acknowledgements}

This work was financially supported by Siemens AG and the Advanced Research Projects Agency for Energy (ARPA-e) division of the United States Department of Energy through grant DEAR0000083.

\section{References}

1 NOAA National Climatic Data Center, State of the Climate: Global Analysis for Annual 2012, 2012.

2 S. A. Marcott, J. D. Shakun, P. U. Clark and A. C. Mix, Science, 2013, 339, 1198-1201.
3 R. Rohde, R. A. Muller, R. Jacobsen, E. Muller, S. Perlmutter, A. Rosenfeld, J. Wurtele, D. Groom and C. Wickham, Geoinfor Geostat, 2013, 1, 1-7.

4 NCADAC, Federal Advisory Committee Draft Climate Assessment Report Released for Public Review, 2013.

5 Climate Change 2007: Impacts, Adaptation and Vulnerability, Contribution of Working Group II to the Fourth Assessment Report of the IPCC, ed. M. L. Parry, O. F. Canziani, J. P. Palutikof, P. J. Van Der Linden and C. E. Hanson, Cambridge University Press, Cambridge, 2007.

6 National Research Council, America's Climate Choices, 2011.

7 EPA, Draft Inventory of U.S. Greenhouse Gas Emissions and Sinks: 1990-2011, 2013, pp. ES-5.

8 MIT, Retrofitting of Coal-Fired Power Plants for $\mathrm{CO}_{2}$ Emissions Reductions. An MIT Energy Initiative Symposium, 2009.

9 US Energy Information Administration, Annual Energy Outlook 2011: With Projections to 2035, 2011.

10 S. Chu, Science, 2009, 325, 1599.

11 P. DiPietro, P. Balash and M. Wallace, A Note on Sources of $\mathrm{CO}_{2}$ Supply for Enhanced Oil Recovery Operations, SPE Economics and Management, 2012.

12 G. T. Rochelle, Science, 2009, 325, 1652-1654.

13 J. T. Cullinane and G. T. Rochelle, Chem. Eng. Sci., 2004, 59, 3619-3630.

14 R. J. Hook, Ind. Eng. Chem. Res., 1997, 36, 1779-1790.

15 R. Idem, M. Wilson, P. Tontiwachwuthikul, A. Chakma, A. Veawab, A. Aroonwilas and D. Gelowitz, Ind. Eng. Chem. Res., 2006, 45, 2414-2420.

16 V. Darde, K. Thomsen, W. J. M. van Well and E. H. Stenby, Energy Procedia, 2009, 1, 1035-1042.

17 D. Singh, E. Croiset, P. L. Douglas and M. A. Douglas, Energy Convers. Manage., 2003, 44, 3073-3091.

18 J. Katzer, E. Moniz, J. Deutch, S. Ansolabehere, J. Beer, et al., The Future of Coal: An Interdisciplinary MIT study, 2007, pp. 146-149.

19 A. Kothandaraman, L. Nord, O. Bolland, H. J. Herzog and G. J. McRae, Energy Procedia, 2009, 1, 1373-1380.

20 M. Ho, G. Allinson and D. Wiley, Ind. Eng. Chem. Res., 2008, 47, 4883-4890.

21 C. E. Powell and G. G. Qiao, J. Membr. Sci., 2006, 279, $1-49$.

22 M. Ho, G. Allinson and D. Wiley, Ind. Eng. Chem. Res., 2008, 46, 1562-1568.

23 P. N. Seevam, J. M. Race, M. J. Downie and P. Hopkins, Proceedings of IPC2008, 2008, pp. 1-13.

24 G. J. Binczewski, JOM, 1995, 47, 20-25.

25 T. Younos and K. E. Tulou, Journal of Contemporary Water Research and Education, 2009, 132, 3-10.

26 W. Ward, Nature, 1970, 227, 162-163.

27 C. A. Koval, S. M. Drew, R. D. Noble and J. Yu, Inorg. Chem., 1990, 29, 4708-4714.

28 P. A. Terry, H. Walls, R. D. Noble and C. A. Koval, AIChE J., 1995, 41, 2556-2564.

29 P. A. Terry, R. D. Noble, D. Swanson and C. A. Koval, AIChE J., 1997, 43, 1709-1716.

30 M. P. Kang and J. Winnick, J. Appl. Electrochem., 1985, 15, 431-439. 
31 H. W. Pennline, E. J. Granite, D. R. Luebke, J. R. Kitchin, J. Landon and L. M. Weiland, Fuel, 2010, 89, 1307-1314.

32 M. D. Eisaman, L. Alvarado, D. Larner, P. Wang, B. Garg and K. a. Littau, Energy Environ. Sci., 2011, 4, 1319.

33 D. L. DuBois, A. Miedaner, W. Bell and J. C. Smart, Electrochemical and Electrocatalytic Reactions of Carbon Dioxide, Elsevier Science Publishers, Amsterdam, 1993, p. 94.

34 A. M. Appel, R. Newell, D. L. DuBois and M. R. i. DuBois, Inorg. Chem., 2005, 44, 3046-3056.

35 P. Scovazzo, J. Poshusta, D. DuBois, C. Koval and R. Noble, J. Electrochem. Soc., 2003, 150, D91.

36 S. Zhou, X. Chen, T. Nguyen, A. K. Voice and G. T. Rochelle, ChemSusChem, 2010, 3, 913-918.

37 O. Trass and R. Weiland, Can. J. Chem. Eng., 2009, 4, 773-781. 38 I. Kim and H. F. Svendsen, Ind. Eng. Chem. Res., 2007, 46, 5803-5809.

39 A. Hartono, K. A. Hoff, T. Mejdell and H. F. Svendsen, Energy Procedia, 2011, 4, 179-186.
40 J.-M. G. Amann and C. Bouallou, Ind. Eng. Chem. Res., 2009, 48, 3761-3770.

41 R. Pflaum and W. Brandt, J. Am. Chem. Soc., 1955, 76, 62156219.

42 J. Hall and W. Dean, J. Am. Chem. Soc., 1958, 80, 4183-4188.

43 J. Carroll, J. Slupsky and A. Mather, J. Phys. Chem. Ref. Data, 1991, 20, 1201-1209.

44 S. Aksu and F. M. Doyle, J. Electrochem. Soc., 2001, 148, B51.

45 C. Alie, L. Backham, E. Croiset and P. L. Douglas, Energy Convers. Manage., 2005, 46, 475-487.

46 K. Shen and M. Li, J. Chem. Eng. Data, 1992, 96-100.

47 H. B. Jonassen, R. B. LeBlanc and R. M. Rogan, J. Am. Chem. Soc., 1950, 72, 4968-4971.

48 H. A. Laitinen, E. I. Onstott, J. C. Bailar and S. Swann, J. Am. Chem. Soc., 1949, 71, 1550-1552.

49 F. Cotton and F. Harris, J. Phys. Chem., 1955, 1203-1208.

50 J. H. Meldon and M. A. Morales-Cabrera, Chem.-Eur. J., 2011, 171, 753-759. 